\title{
A CLINICAL STUDY ON CARDIOVASCULAR MANIFESTATIONS SECONDARY TO CIRRHOSIS OF LIVER
}

\author{
Arvind M. N1, Shilpa Patel2 2 Balraj K. P3
}

${ }^{1}$ Associate Professor, Department of Internal Medicine, KIMS, Bengaluru.

${ }^{2}$ Medical Registrar, Department of Internal Medicine, Apollo Hospital, Malleshwaram.

${ }^{3}$ Professor, Department of Internal Medicine, KIMS, Bengaluru.

ABSTRACT
BACKGROUND
Cirrhosis of liver is a hyperdynamic condition, in which there may be subtle cardiac dysfunction. The aim of this study is to
determine the occurrence of cardiovascular changes among patients with cirrhosis of liver, irrespective of aetiology and its
association with QTc variation.

\section{MATERIALS AND METHODS}

This study was a case control study. 30 patients with cirrhosis of liver and 30 controls matched for age and sex were subjected to clinical examination followed by ECG and 2D echo to screen for cardiac abnormalities. QTc interval, E/A ratio and LV mass were calculated.

\section{RESULTS}

M: F ratio was 4: 1 with the mean age of $51.5 \mathrm{yrs} .73 .3 \%$ of the cases were alcoholics. Mean QTc prolongation was $473 \mathrm{~ms}$ and significant QTc prolongation was 73\% of CPC. Mean LV mass was $186 \mathrm{~g}$ and 78.5\% of patients in CP-C had elevated LV mass. The mean E/A ratio was 0.85 and $53.3 \%$ of patients with E/A ratio $\leq 1$ and mean EF of $55 \%$ with $1 / 3$ rd of the patients with EF $<50 \%$. No significant change was noted in the control group with respect to QTc, LV mass and E/A ratio.

\section{CONCLUSION}

QTc prolongation, LV mass and E/A ratio assessment in cirrhotics along with Child-Pugh grade can be used to determine the severity of the underlying cardiac abnormality and predict the prognosis of the patient.

\section{KEYWORDS}

CP- Child-Pugh, Cirrhosis of Liver, Cardiac Abnormalities, E/A Ratio, LV Mass.

HOW TO CITE THIS ARTICLE: Arvind MN, Patel S, Balraj KP. A clinical study on cardiovascular manifestations secondary to cirrhosis of liver. J. Evolution Med. Dent. Sci. 2018;7(03):264-268, DOI: 10.14260/jemds/2018/59

\section{BACKGROUND}

Cirrhosis is a common hepatological disorder seen in clinical practice. It is characterised by replacement of liver tissue by fibrosis and regenerative nodules. The clinical picture of patients with cirrhosis is dominated by the classical complications such as ascites, bleeding from oesophageal varices, portal hypertension and encephalopathy. In addition, a considerable number of patients showed signs of peripheral vasodilatation with palmar erythema and reddish skin, raised and bounding pulse, and a low systemic blood pressure indicating a hyperdynamic circulation.

Increased cardiac output in cirrhosis was described more than 50 years ago and a hyperdynamic, hyporeactive circulation is today a well-characterised element in the clinical appearance of these patients. In addition, patients with cirrhosis develop complications from a variety of organs including the heart, lungs and kidneys, and other organ systems. Besides the hepatorenal syndrome this has led to the recognition of new clinical entities, such as cirrhotic cardiomyopathy and the hepatopulmonary syndrome.

'Financial or Other Competing Interest': None.

Submission 26-12-2017, Peer Review 06-01-2018,

Acceptance 09-01-2018, Published 13-01-2018.

Corresponding Author:

Dr. Arvind M. N,

\#42/1, $9^{\text {th }}$ Main, $4^{\text {th }}$ Cross

RMV Extension, Sadashivnagar,

Bangalore-560080.

E-mail: drarvind_mn@yahoo.co.in

DOI: $10.14260 /$ jemds $/ 2018 / 59$
Cardiomyopathy is derived from the Greek words cardio (heart) + mys (muscle) + pathos (disease), that is it is a condition affecting the heart muscles. Cardiomyopathy is broadly divided into 3 basic types: dilated cardiomyopathy, in which the heart muscles become weak and the cardiac chambers subsequently dilate; hypertrophic cardiomyopathy, in which the heart muscles themselves are much thicker than normal; and restrictive cardiomyopathy, in which the heart becomes stiff and cannot fill efficiently during diastole. Any of these abnormalities can affect cardiac function, be it systolic function, diastolic function or rhythm conduction.

It can be diagnosed by using a combination of electrocardiograph, 2-dimensional echocardiography and various serum markers such as brain natriuretic factor.

The underlying pathogenetic mechanisms include abnormalities in the $\beta$-adrenergic signalling pathway, altered cardiomyocyte membrane fluidity, increased myocardial fibrosis, cardiomyocyte hypertrophy and ion channel defects. Various compounds for which levels are elevated in cirrhosis such as nitric oxide and carbon monoxide can also exert a negative inotropic effect on the myocardium, whereas excess sodium and volume retention can lead to myocardial hypertrophy. Various toxins can also aggravate the ion channel defects, thereby widening the QRS complex causing prolonged QT intervals. Clinically, systolic incompetence is most evident when cirrhotic patients are placed under stress, whether physical or pharmacological or when the extent of peripheral arterial vasodilatation demands an increased cardiac output as in the case of bacterial infections. Treatment of cirrhotic cardiomyopathy is unsatisfactory. 
There is some evidence that $\beta$-blockade may help some cirrhotic patients with baseline prolonged QT interval. Longterm aldosterone antagonism may help reduce myocardial hypertrophy. Future studies should include further elucidation of pathogenetic mechanisms, so as to develop effective treatment strategies.

Recognition of cirrhotic cardiomyopathy will depend on a high level of awareness for this syndrome and potentially will help better manage patients with cirrhosis.

This study aims to assess the cardiac status in patients with cirrhosis of liver in comparison to healthy controls and also to the occurrence of cirrhotic cardiomyopathy, to study if the Electrocardiography, echocardiographic parameters of cardiac dysfunction correlate with the severity of liver dysfunction.

\section{MATERIALS AND METHODS \\ Study Design}

Case control study.

\section{Study Sampling}

Purposeful sampling.

\section{Duration of Study}

Study was done over a period of 18 months from November 2012 to April 2014.

\section{Sample Size}

60 (30 cases and 30 controls) satisfying inclusion and exclusion criteria were selected. Sample size was taken conveniently.

\section{Inclusion Criteria}

Age group > 18 yrs.

Patients with clinical features and investigation suggestive of cirrhosis of liver, alcoholic subjects being abstinent from alcohol from the past six months.

\section{Exclusion Criteria}

Patients with suspected liver malignancy.

Patients with ischaemic heart disease, valvular heart disease, conduction defects, cardiac failure and atrial fibrillation.

Patients already on medications which alter QTc like quinidine, phenothiazine, TCA.

Known Hypertensive or Diabetic.

\section{Source of Data}

All Inpatients of KIMS Hospital admitted during the period from 1st November 2012 to 30th April 2014.

\section{Method of Collection of Data}

All the patients admitted to KIMS Hospital during the period of November 2012 to April 2014, who are fitting into the inclusion criteria will be taken into the study.

All study subjects will be selected from patients admitted in Kempegowda Institute of Medical Sciences, Bangalore from November 2012 to April 2014 and fulfilling the inclusion and exclusion will be included in this study.

30 Cases will be selected on the basis of clinical presentation and investigation findings.

30 Controls matched for age and sex willing to give informed consent will be included in the study.
Detailed history, clinical examination and necessary investigation will be done for both cases and controls.

The following Investigations were done for all the study subjects after taking their consent-

- Complete haemogram.

- Serum electrolytes.

- RBS.

- Liver function tests.

- ECG.

- 2D Echo.

- USG Abdomen.

- Urine routine.

- PT-INR.

- aPTT.

- BT.

- CT.

Significance is assessed at $5 \%$ level of significance. The following Assumptions on Data are made-

Dependent variables should be normally distributed.

Samples drawn from the population should be random, cases of the samples should be independent.

\section{Statistical Method}

Data was analysed using SPSS Version 16. Statistical data and variables obtained from the patients will be analysed using student ' $\mathrm{t}$ ' test and Chi-square test. Descriptive statistical analysis has been carried out in the present study. Results on continuous measurements are presented on Mean ? SD (MinMax) and results on categorical measurements are presented in Number (\%).

Student ' $\mathrm{t}$ ' test (two-tailed, independent) has been used to find the significance of study parameters on continuous scale between two groups (Intergroup analysis) on metric parameters. Levene's test for homogeneity of variance has been performed to assess the homogeneity of variance. Chisquare test has been used to find the significance of study parameters on categorical scale between two or more groups.

\section{Significant Figures}

+ Suggestive significance ( $\mathrm{P}$ value: $0.05<\mathrm{P}<0.10$ )

* Moderately significant (P value: $0.01<\mathrm{P}$ ? 0.05 )

** Strongly significant (P value: $\mathrm{P}$ ? 0.01 )

\section{RESULTS}

In our study, $80 \%$ (24) of patients were males and $20 \%$ (6) were females. Out of the 30 patients included in the study, the incidence was found to be high in the elderly with the maximum number of cases observed in the $40-70$ years' age group. The mean age of the controls was 44.5 years and that of the cases was 51.5 years.

In our study, the mean BMI was noted to be 24.1 in cases and 28.0 among controls. In our study, the most common aetiology of cirrhosis was found to be alcoholic liver cirrhosis $(73.3 \%)$ followed by viral aetiology (hepatitis B- $13.3 \%$ and hepatitis C- 6.7\%) and cryptogenic (6.7\%).

The Child-Pugh score of majority of the patients was $\mathrm{C}$ (46.7\%) followed by B (40.0\%) and C (13.3\%).

Majority of the patients had a Child-Pugh score of B $(\mathrm{N}=12)$ and $\mathrm{C}(\mathrm{N}=14)$ with males occupying $66.7 \%$ and $92.9 \%$ in each respectively. 
The predominant habit was alcoholism (73.3\%) and leading signs were oedema (80\%) and icterus (73.3\%). The other signs were pallor (13.3\%), glossitis (13.3\%), gynaecomastia (20\%) and spider naevi (20\%) satisfying the inclusion criteria.

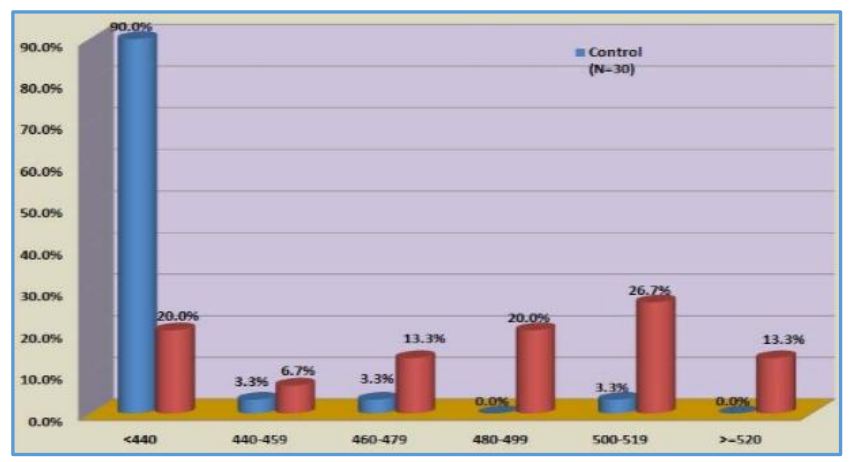

Figure 1. Distribution of QTc values among Cases and Controls Group

X axis - QTc interval, Y axis - Percentage of cases and control.

\begin{tabular}{|c|c|c|c|c|c|c|c|}
\hline QTC & Control & & Case & & Total & & P Value \\
\hline$<440$ & 27 & $90.0 \%$ & 6 & $20.0 \%$ & 33 & $55.0 \%$ & \multirow{6}{*}{$<0.001$} \\
\hline $\begin{array}{c}440- \\
459\end{array}$ & 1 & $3.3 \%$ & 2 & $6.7 \%$ & 3 & $5.0 \%$ & \\
\hline $\begin{array}{c}460- \\
479\end{array}$ & 1 & $3.3 \%$ & 4 & $13.3 \%$ & 5 & $8.3 \%$ & \\
\hline $\begin{array}{c}480- \\
499\end{array}$ & 0 & $0.0 \%$ & 6 & $20.0 \%$ & 6 & $10.0 \%$ & \\
\hline $\begin{array}{c}500- \\
519\end{array}$ & 1 & $3.3 \%$ & 8 & $26.7 \%$ & 9 & $15.0 \%$ & \\
\hline$>=520$ & 0 & $0.0 \%$ & 4 & $13.3 \%$ & 4 & $6.7 \%$ & \\
\hline
\end{tabular}

Most of the controls, i.e. $90 \%$ of patients had a QTc interval of $<440$. Amongst the cases, it was distributed from $<440$ to $>=520$.

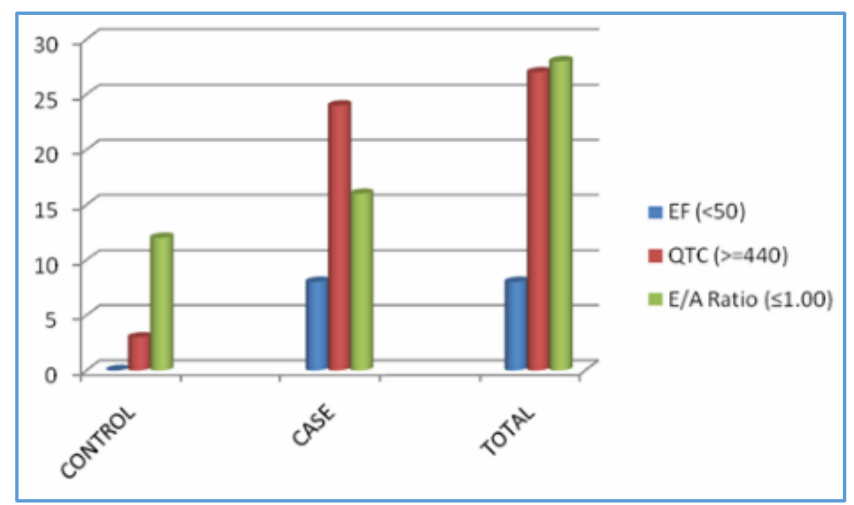

Figure 2. Comparison of EF, QTC and E/A Ratio among Cases and Controls

\begin{tabular}{|c|c|c|c|c|c|c|c|}
\hline & Control & Cases & \multicolumn{2}{|c|}{ Total } & P value \\
\hline $\mathrm{EF}(<50)$ & 0 & $0.0 \%$ & 8 & $26.7 \%$ & 8 & $13.3 \%$ & 0.002 \\
\hline $\mathrm{QTC}(>=440)$ & 3 & $10.0 \%$ & 24 & $80.0 \%$ & 27 & $45.0 \%$ & $<0.001$ \\
\hline $\begin{array}{c}\text { E/A Ratio } \\
(\leq 1.00)\end{array}$ & 12 & $40.0 \%$ & 16 & $53.3 .0 \%$ & 28 & $47.0 \%$ & 0.417 \\
\hline \multicolumn{7}{|c|}{ Table 2. Comparison of EF, QTc and E/A Ratio } \\
among Cases and Controls \\
\hline
\end{tabular}

On comparison between controls and cases, QTc was prolonged $>440 \mathrm{~ms}$ in higher number of cases $(80 \%)$ than controls (10\%). Diastolic dysfunction with reduced E/A ratio was noted in $53.3 \%$ of cases and only in $40 \%$ of controls. Ejection fraction was also noted to be $<50 \%$ in $26.7 \%$ of cases.

Chamber dilatation was noticed to be absent in majority of the cases $(73.3 \%)$ in our study, while $20 \%$ had LALV dilatation and $6.7 \%$ had LARV dilatation.

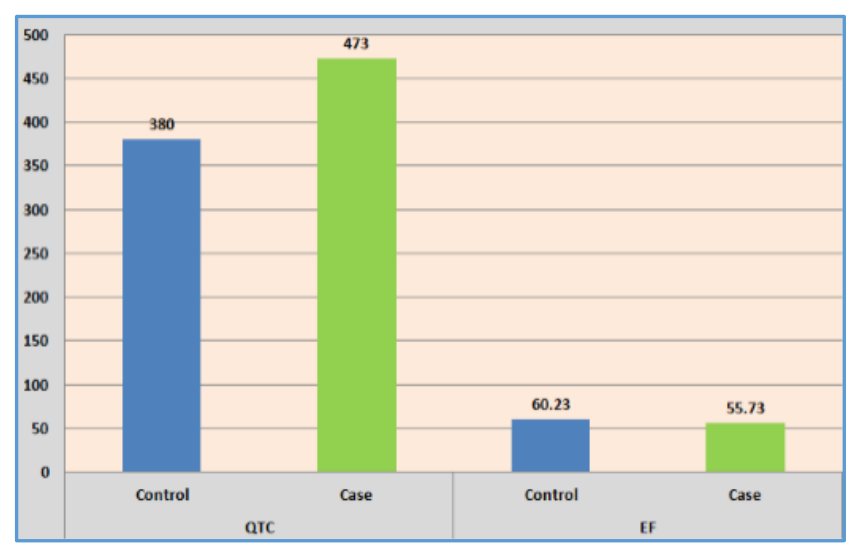

Figure 3. Comparison of Mean Values of QTC and EF between Cases and Controls

\begin{tabular}{|c|c|c|c|c|c|c|c|c|}
\hline & & $\mathbf{N}$ & Mean & SD & Median & Min & Max & $\begin{array}{c}P \\
\text { value }\end{array}$ \\
\hline \multirow[b]{2}{*}{$\mathrm{EF}$} & Control & 30 & 60.23 & 3.104 & 60.00 & 55 & 67 & \multirow{2}{*}{0.008} \\
\hline & Case & 30 & 55.73 & 8.424 & 58.50 & 30 & 68 & \\
\hline \multirow[b]{2}{*}{ QTC } & Control & 30 & 380.0 & 46.461 & 390.0 & 300 & 510 & \multirow{2}{*}{$<0.001$} \\
\hline & Case & 30 & 473.0 & 46.025 & 485.0 & 360 & 540 & \\
\hline
\end{tabular}

The mean Ejection Fraction of cases was 55.73\% compared to an EF of $60.23 \%$ of the controls. Compared to a mean QTc interval of 380.0 milliseconds of controls, the cases had a mean QTc interval of 473.0 milliseconds.

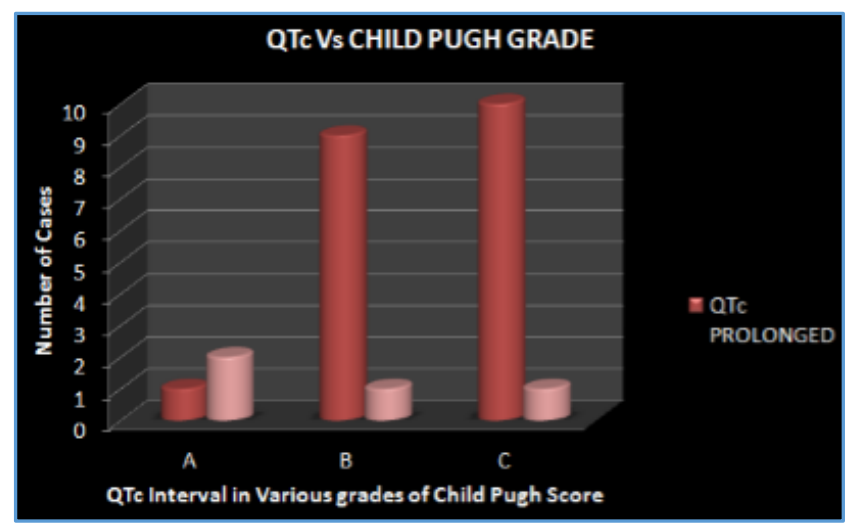

Figure 4. QTc vs. Child-Pugh Grade

\begin{tabular}{|c|c|c|}
\hline QTc & $\mathbf{> 4 4 0} \mathbf{~ m s}$ & $<\mathbf{4 4 0} \mathbf{~ m s}$ \\
\hline A & 1 & 3 \\
\hline B & 9 & 3 \\
\hline C & 12 & 2 \\
\hline \multicolumn{2}{|c|}{ Table 4. QTc vs. Child-Pugh Grade } \\
\hline
\end{tabular}


Majority of patients with Child-Pugh score of C (86\%) and score B (75\%) had a prolonged QTc interval of $>440 \mathrm{~ms}$.

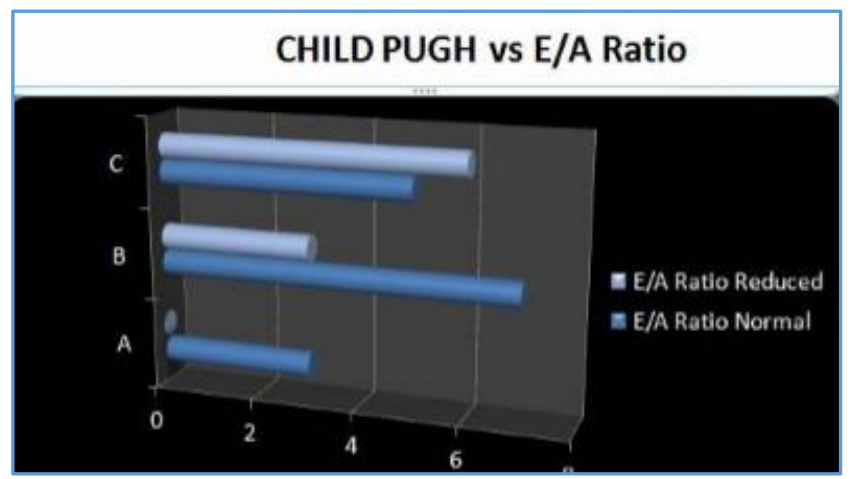

Figure 5. Child-Pugh vs. E/A Ratio

$\mathrm{X}$ axis: Child-Pugh Class, $\mathrm{Y}$ axis: E/A ratio percentile.

\begin{tabular}{|c|c|c|}
\hline Child-Pugh & E/A Reduced & E/A Normal \\
\hline A & 0 & 4 \\
\hline B & 6 & 6 \\
C & 9 & 5 \\
\hline \multicolumn{2}{|r|}{ Table 5. Child-Pugh vs. E/A Ratio } \\
\hline
\end{tabular}

Our study showed that there was reduced E/A ratio indicating diastolic dysfunction with higher Child-Pugh scores of B (50\%) and C (65\%). E/A ratio was normal with Child-Pugh score A.

\section{DISCUSSION}

\section{Aetiology of Cirrhosis}

The most predominant cause of cirrhosis of liver in this study was alcoholism with $73 \%$ of the study population being alcoholics. The rest $27 \%$ of the population consisted of chronic hepatitis patients (22\%) and other unknown causes of cirrhosis in comparison to the Wong $\mathrm{F}$ et al[1] study, which had $68.5 \%$ alcoholics and $17.1 \%$ cases of chronic hepatitis.

\begin{tabular}{|l|c|c|c|}
\hline Etiology & Present study & Wong et al & K. Mimidis et al \\
\hline Alcoholic & 22 & 24 & 29 \\
\hline Hepatitis & 6 & 6 & 23 \\
\hline Others & 2 & 5 & 0 \\
\hline
\end{tabular}

Table 6. Aetiology of Cirrhosis

The cardiac abnormalities in the group did not show any significant correlation to any particular aetiology. This impresses upon the importance of latent cardiac abnormalities in cirrhosis patients, irrespective of the cause for which they should be screened. This observation is also in accordance with the Pozzi $\mathrm{M}$ et al[2] study, which found no difference in the cardiac abnormalities caused by alcoholic cirrhosis and those by post viral cirrhosis along with stating that the diastolic dysfunction in the subjects were unlikely to be caused by the toxic effects of ethanol on the heart.

\section{Clinical Features in Cirrhosis}

The most common presenting symptoms were abdominal distension, fatigue followed by abdominal pain. In this series, $86.7 \%$ of the patients had complaints of abdominal distension and $56.7 \%$ had complaints of fatigue and $50 \%$ had abdominal pain.
Incidence of haematemesis and breathlessness were low. Clinically, all the patients had moderate-to-severe ascites. Oedema was seen in $80 \%$ of the cases and icterus was noticed in $73.3 \%$ of the cases. Signs of liver cell failure were noticed only in $20 \%$ of the cases, of which correlation with structural or functional cardiac function was not significant. Hence, highlighting the importance of cardiac screening in patients who present with minimal or no signs of liver cell failure.

\section{ECG Changes and Cardiac Abnormalities in Cirrhosis}

Our study confirms the QTc prolongation in subgroups of cirrhotic patients representing the two major causes of cirrhosis: alcoholic and post viral. The results were similar in a way that suggests the independence of QTc prolongation from the aetiology of cirrhosis. This may imply that the QTc prolongation in cirrhosis is a phenomenon, which derives from the pathophysiology of cirrhosis itself and does not reflect a primary abnormality related to certain causes of cirrhosis.

\begin{tabular}{|c|c|}
\hline & QTc Prolongation \\
\hline K. Mimidis et al & $43(82.6 \%)$ \\
\hline Bernardi et al & $44(46 \%)$ \\
\hline Michael Fu et al & $186(60 \%)$ \\
\hline Ioana Mozos et al & $36(94 \%)$ \\
\hline Present Study & $24(80 \%)$ \\
\hline \multicolumn{2}{|c|}{ Table 7. Incidence ofQTc Prolongation } \\
\hline
\end{tabular}

Additionally, our study focuses on the relationship of QTc prolongation with the severity of the disease. Although, it fails to statistically confirm QTc prolongation for Child-Pugh cirrhotic patients, the statement becomes true for Child-Pugh $\mathrm{B}$ and $\mathrm{C}$ cirrhotic patients.

Prolongation of the QTc interval was statistically confirmed in Child-Pugh C and B groups $(0,489$ sec, $\mathrm{P}=0$, 0019 and 0,480 sec, $\mathrm{P}=0,0002$ respectively) but not in ChildPugh A group $(0,445$ sec, $P=0,4366)$. There was a statistically significant difference between Child-Pugh group $C$ and $A(P=0,0004)$ as well as between $B$ and $A(P=0,0010)$, but not between $B$ and $C(P=0,5453)$.

\begin{tabular}{|l|c|c|c|}
\hline QTc prolongation & CHILD PUGH & CLASS & \\
\hline & A & B & C \\
\hline loana Mozos et al & $462 \mathrm{~ms}$ & $493 \mathrm{~ms}$ & $520 \mathrm{~ms}$ \\
\hline K. Mimidis et al & $446 \mathrm{~ms}$ & $480 \mathrm{~ms}$ & $489 \mathrm{~ms}$ \\
\hline Present study & $460 \mathrm{~ms}$ & $492 \mathrm{~ms}$ & $\mathbf{5 0 3 m s}$ \\
\hline
\end{tabular}

Table 8. QTc Prolongation in Relation to Child-Pugh Class

QT Interval and Liver Cirrhosis Aetiology

\begin{tabular}{|l|l|c|c||}
\hline $\begin{array}{l}\text { Liver } \\
\text { disease } \\
\text { etiology }\end{array}$ & $\begin{array}{l}\text { loana } \\
\text { Mozos et } \\
\text { al }\end{array}$ & K. Mimidis et al & Present study \\
\hline $\begin{array}{c}\text { Alcoholism } \\
\begin{array}{c}\text { Virus } \\
\text { related }\end{array}\end{array}$ & $527 \mathrm{~ms}$ & $471 \mathrm{~ms}$ & $498 \mathrm{~ms}$ \\
\hline \begin{tabular}{l} 
Others \\
\hline
\end{tabular} & $479 \mathrm{~ms}$ & $468.5 \mathrm{~ms}$ & $487.5 \mathrm{~ms}$ \\
\hline
\end{tabular}

Table 9. QT Interval and Liver Cirrhosis Aetiology 
Several investigators have previously confirmed the prolongation of the QT interval in cirrhosis.

This anomaly was unrelated to the aetiology of cirrhosis, but was positively related with the severity of the disease as expressed by Child-Pugh score.

The results were similar in a way that suggests the independence of QTc prolongation from the aetiology of cirrhosis. This may imply that the QTc prolongation in cirrhosis is a phenomenon, which derives from the pathophysiology of cirrhosis itself and does not reflect a primary abnormality related to certain causes of cirrhosis. Echocardiographic parameters.

LV mass was significantly raised in $70 \%$ of the study population with a mean value of $186.3 \pm 32.980 \mathrm{gm}$, which in accordance with Wong et al[1] study and e/a ratio being $\leq 1$ in $53.3 \%$ of population in comparison to Massimo et al[3] and Wong et al studies, where the LV mass being $172 \pm 25.09$ and $171.4 \pm 20.04$ and e/a ratio being 0.97 and $0.9 \pm 0.1$.

\begin{tabular}{|l|c|c|c|}
\hline Parameters & Present study & Wong et al & Massimo et al \\
\hline LV mass(gms) & $186 \pm 32.980$ & $171.4 \pm 20.04$ & $172 \pm 25.09$ \\
\hline E/A ratio & $0.85 \pm 0.16$ & $0.9 \pm 0.1$ & 0.97 \\
\hline
\end{tabular}

Table 10. Echocardiographic Parameters

The major cardiac structural abnormality of the myocardium in such patients was myocardial hypertrophy. One possible explanation for this would be myocardial adaptation to a chronically elevated blood volume.

Alternatively, ventricular hypertrophy or remodelling could be related to the trophic effects of activated neurohormonal systems such as noradrenaline or angiotensin II with or without the synergistic effects of endothelin- $1 .^{4}$

Studies have proven that there is E/A normalisation in patients that receive liver transplant, LV ejection fraction.

\begin{tabular}{|l|c|c|c|}
\hline Parameter & Present study & Wong et al & Massimo et al \\
\hline LVEF & $55.73 \pm 0.97$ & $62.7 \pm 3.6$ & $61 \pm 2.5$ \\
\hline
\end{tabular}

Table 11. LV Ejection Fraction

LV ejection fraction showed a mean value of 55.73 in the study population. LVEF was normal in most of the patients of the study group with mean value of $55.73 \pm 0.97 \%$, similar to results in below mentioned studies. This paradoxical normal $\mathrm{EF}$ value in the face of diastolic dysfunction could probably be because of normal pre and after load of the cirrhotic heart as explained by Moller et al.[5]

\section{CONCLUSION}

- In conclusion, the QTc interval is elongated in cirrhotic patients independently of the aetiology of cirrhosis, more so in Child-Pugh B and C. The reason for this abnormality remains unclear.

- Incidence of reduced E/A ratio indicating diastolic dysfunction increases with Child-Pugh scores of B and C.

- $\quad$ Nevertheless, the additional risk for severe arrhythmias and sudden death should be evaluated and assessed before any pharmaceutical or iatrogenic intervention is undertaken in these patients.

- $\quad$ ECG changes were seen in $80 \%$ of the cases.

- Mean QTc prolongation was $473 \mathrm{~ms}$.

- $\quad$ Significant QTc prolongation in $73.3 \%$ of Child-Pugh score $\mathrm{C}$.

- Mean LV mass of 186 gms was obtained.

- The Mean E/A ratio was 0.85 and $53.3 \%$ of patients had $\mathrm{E} / \mathrm{A}$ ratio $\leq 1$.

- Mean EF of $55 \%$ with $1 / 3$ rd of the patients with $\mathrm{EF}<$ $50 \%$.

- Structural cardiac abnormality (70\%) was higher compared to functional cardiac dysfunction (53.3\%).

\section{REFERENCES}

[1] Wong F, Liu P, Lilly L, et al. Role of cardiac structural and functional abnormalities in the pathogenesis of hyperdynamic circulation and renal sodium retention in cirrhosis. Clinical Science (London) 1999;97(3):259-67.

[2] Pozzi M, Carugo S, Boari G, et al. Evidence of functional and structural cardiac abnormalities in cirrhotic patients with and without ascites. Hepatology 1997;26(5):1131-7.

[3] Cazzaniga M, Salerno F, Pagnozzi G, et al. Diastolic dysfunction is associated with poor survival in patients with cirrhosis with transjugular intrahepatic portosystemic shunt. Gut 2007;56(6):869-75.

[4] Yamazaki T, Komuro I, Kudoh S, et al. Endothelin-1 is involved in mechanical stress-induced cardiomyocyte hypertrophy. J Biol Chem 1996;271(6):3221-8.

[5] Møller S, Dümcke CW, Krag A. The heart and the liver. Expert Rev Gastroenterol Hepatol 2009;3(1):51-64. 